\title{
Erratum to: an update on addressing important peripheral nerve problems: challenges and potential solutions
}

\author{
Wilson Z. Ray ${ }^{1} \cdot$ Mark A. Mahan $^{2} \cdot$ Danzhu Guo $^{3} \cdot$ Danqing Guo $^{3} \cdot$ Michel Kliot $^{4}$
}

Published online: 29 May 2017

(C) Springer-Verlag Wien 2017

\section{Erratum to: Acta Neurochir}

DOI 10.1007/s00701-017-3203-3

Caption for Fig. 7 is incorrect in the initially published version. The correct fig. 7 caption is given below and the original article was corrected.
The online version of the original article can be found at http://dx.doi.org/ $10.1007 / \mathrm{s} 00701-017-3203-3$

Michel Kliot

mkliot@stanford.edu

1 Department of Neurosurgery, Washington University School of Medicine, St. Louis, MO 63110, USA

2 Department of Neurosurgery, University of Utah, Salt Lake City, UT 84132, USA

3 BayCare Clinic, Green Bay, WI 54303, USA

4 Department of Neurosurgery, Stanford University School of Medicine, Palo Alto, CA 94304, USA

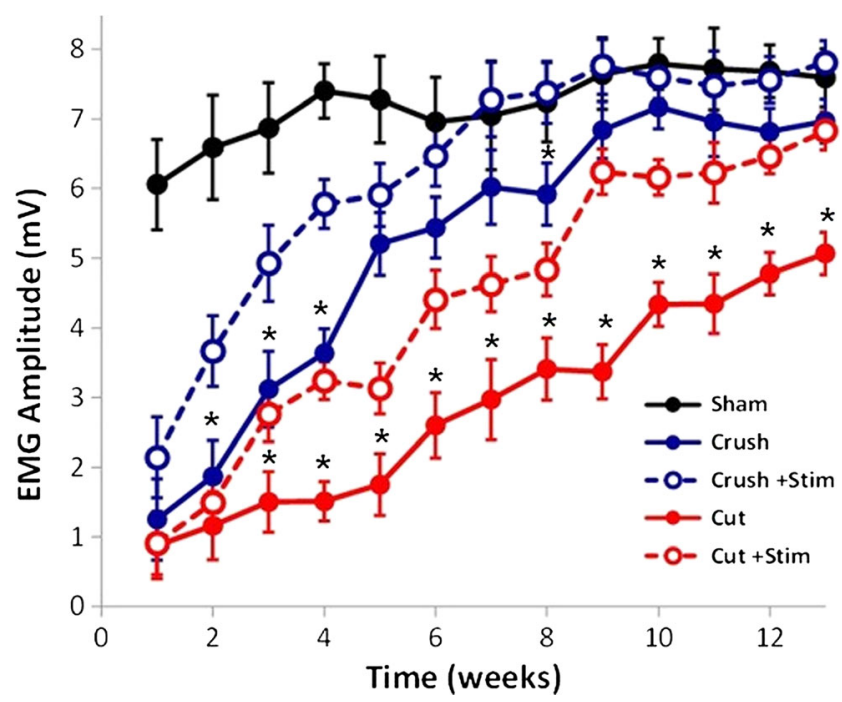

Fig. 7 Maximum amplitude of electromyograms (EMGs) evoked in plantaris muscles (PL) upon electrical activation of uninjured, crushed, and cut and repaired sciatic nerve both in the presence and absence of brief electrical stimulation via implanted wireless nerve stimulator. Mean values and standard deviations are shown. $*$ denotes $p<0.05$ versus timematched injury model without brief electrical stimulation 